\title{
Health leadership training academy tackles worst first
}

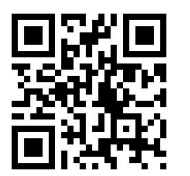

Health Minister Dr Aaron Motsoaledi's bid to overhaul dysfunctional and often inept leadership at public hospitals has got off to a solid start, with his custom-made Academy for Leadership and Management in Health Care tackling 'a couple of fire-fighting tasks'

So said the Chairperson of the new academy's Advisory Committee and former Dean of the Faculty of Health Sciences at the University of Cape Town, Professor Marian Jacobs. In February she corralled 84 of the 103 most recently appointed (or reappointed) hospital CEOs for a seminal orientation 'roadmapping' workshop. This group represents the first fruits of Motsoaledis slow but deliberate trimming away of dead wood - 'slow' because of the country's stringent labour laws. $\mathrm{He}$ has assessed a quarter of the national hospital leadership so far.

Also present at the workshop was Dr Carol Marshall, who is tasked with setting up and running the pivotal Office for Healthcare Standards Compliance (finally rendered legal last month by an act of Parliament). Marshall has developed a tool for assessing quality at hospitals with minimum standards set for their accreditation to the incoming National Health Insurance (NHI), enabling them to qualify for NHI funding. This tool has been adapted for assessing hospital managers, which is why Dr Marshall is an essential partner for the academy.

Jacobs said her second fire-fighting task had been to set up another workshop in May, consisting mainly of the strife- and controversy-ridden Limpopo Province's hospital CEOs, quality managers and some district teams. All participants in both workshops were asked to develop 100-day plans, both personal and institutional, which would be monitored and supported by Dr Terence Carter, newly appointed Deputy Director-General: Hospitals Tertiary Service and Workforce Management as of 1 June, and Limpopo Province's new Health Director General, Dr Sipho Khabane, formerly the DG of Health in the Free State and appointed on 1 September.

\section{'Fix the entire management chain' - hospital CEOs}

The most valuable (and loudest) feedback from the national CEO group was that their

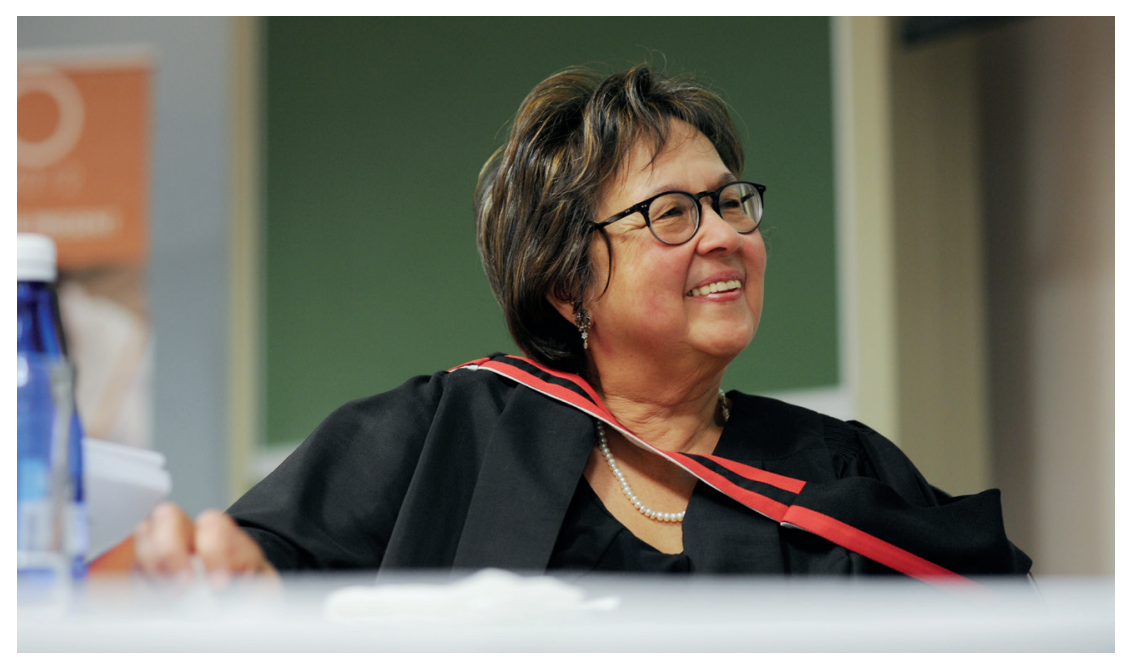

Professor Marian Jacobs, Chief Advisor for the Academy for Leadership and Management in Health Care.

success relies on having appropriately qualified, properly appointed managers below them, and the leadership and management chain above them being competent and functional. Jacobs summarised: 'They asked us to make sure that the nature and competencies of all managers in the system were aligned with their qualifications - and to look at the line going up to provincial and national levels - and also the teams within these institutions. Other critical issues they wanted addressed were on-the-job support and mentoring, peer networking and a clear determination of their own "delegations" [job descriptions].'

Jacobs was unable to say if there had been any progress in addressing the other aspects underlying the systemic problems, but noted that a concurrent national probe is exploring the scope and nature of dysfunction at district level.

She said Khabane will 'follow up and support' the CEOs and other managers who attended the Limpopo workshop. According to Motsoaledi, Limpopo's health department was placed under national administration last year because of mismanagement, not a shortage of money. (It is one of five Limpopo departments that the national health department took over in 2012.) The province overspent by R450 million in the previous financial year, but this has largely been cleared. Motsoaledi revealed that 78 Limpopo health managers are being investigated and will face either disciplinary enquiries or criminal charges. A concurrent probe by the national health department's
Chief Operations Officer, Nobayeni Dladla, had identified a host of shortcomings in the province's healthcare operations. For example, half of Limpopo's 40 hospitals were without functioning boilers, which compromised laundry, bathing and equipment sterilisation - and surgery. Basics such as toilet paper and soap were being sourced on a quotation basis instead of via the national tender system, in direct breach of the Public Finance Management Act. New X-ray machines were standing idle because they came from suppliers without the required import permits, leading the radiation control department to veto their use.

\section{Academy to 'hold it all together}

Jacobs said her advisory committee has done the initial work and is now 'handing the rest of the fire-fighting to the various line authorities'. She explained that the academy, which has an estimated R10 million budget, is intended to act as a focal point for all activities involving training and support for leadership/management, at all levels of care. It will link together and standardise the numerous existing programmes into a single, needs-appropriate 'virtual' network, drawing on the best available expertise.

'We're beginning to identify who is doing what [in leadership and management development and support] and linking with the portfolios of various deputy [national health] DGs, the Office of Health Standards Compliance, and with provincial leadership 
and management focal points, plus many others in this field - so it's quite challenging. There are institutions that have already done significant work on the competencies of district managers, so we'll be linking up with them too', she explained.

Externally, her committee is connecting with global organisations doing similar work. At the time of writing she was consolidating recommendations from the Limpopo workshop for presentation to Motsoaledi, while consulting with various educational authorities to set up a 'knowledge management hub' to promote peer networking, with a 'go-to' website under construction. Jacobs emphasised that Motsoaledi will be guiding her team regarding which provinces need help next, 'because that's where the action has to be focused'.

The initiative is one of the beneficiaries of the R40 million South African Joint Public Health Enhancement Fund. Set up by Motsoaledi in November last year, the fund aims to urgently expand national capacity for training healthcare professionals; build and improve the management cadre; and boost high-level research into HIV/AIDS and tuberculosis.

\section{Chris Bateman}

chrisb@hmpg.co.za

S Afr Med J 2013;103(10):707-708

DOI:10.7196/SAMJ.7480 